\title{
Propene Adsorption-Chemisorption Behaviors on H-SAPO-34 Zeolite Catalysts at Different Temperatures
}

\author{
Muhammad Usman ${ }^{1, *(\mathbb{D})}$, Jiang Zhu ${ }^{2}$, Kong Chuiyang ${ }^{2}$, Muhammad Tahir Arslan ${ }^{2}$, \\ Abuzar Khan ${ }^{1}$, Ahmad Galadima 1,3, Oki Muraza ${ }^{1}$, Ibrahim Khan ${ }^{4}$, Aasif Helal ${ }^{1}$, \\ Bassem A. Al-Maythalony ${ }^{5}$ and Zain H. Yamani ${ }^{1}$ \\ 1 Center of Excellence in Nanotechnology, King Fahd University of Petroleum and Minerals, KFUPM, \\ Dhahran 31261, Saudi Arabia; abuzar@kfupm.edu.sa (A.K.); ahmadgldm@yahoo.com (A.G.); \\ omuraza@kfupm.edu.sa (O.M.); aasifh@kfupm.edu.sa (A.H.); zhyamani@kfupm.edu.sa (Z.H.Y.) \\ 2 Department of Chemical Engineering, Tsinghua University Beijing 100084, China; \\ zhu13062969@163.com (J.Z.); kongchuiyan123@163.com (K.C.); mtahirarslan@hotmail.com (M.T.A.) \\ 3 Center for Research, Federal University Gusau, P.M.B. 1001, Gusau, Zamfara State, Nigeria \\ 4 Center of Integrative Petroleum Research, King Fahd University of Petroleum and Minerals, KFUPM Box \\ 5040, Dhahran 31261, Saudi Arabia; ibrahim.zarin@kfupm.edu.sa \\ 5 King Abdulaziz City for Science and Technology-Technology Innovation Center on Carbon Capture and \\ Sequestration (KACST-TIC on CCS) at King Fahd University of Petroleum and Minerals, \\ Dhahran 31261, Saudi Arabia; bmayth@kfupm.edu.sa \\ * Correspondence: muhammadu@kfupm.edu.sa; Tel.: +966-138608539; Fax: +966-138607264
}

Received: 12 October 2019; Accepted: 31 October 2019; Published: 5 November 2019

check for updates

\begin{abstract}
Propene is an important synthetic industrial product predominantly formed by a methanol-to-olefins (MTO) catalytic process. Propene is known to form oligomers on zeolite catalysts, and paramters to separate it from mixtures and its diffusion properties are difficult to measure. Herein, we explored the adsorption-chemisorption behavior of propene by choosing SAPO-34 zeolites with three different degrees of acidity at various adsorption temperatures in an ultra-high-vacuum adsorption system. H-SAPO-34 zeolites were prepared by a hydrothermal method, and their structural, morphological, and acidic properties were investigated by XRD, SEM, EDX, and temperature-programmed desorption of ammonia ( $\left.\mathrm{NH}_{3}-\mathrm{TPD}\right)$ analysis techniques. The XRD analysis revealed the highly crystalline structure which posses cubic morphology as confirmed by SEM images. The analysis of adsorption of propene on SAPO-34 revealed that a chemical reaction (chemisorption) was observed between zeolite and propene at room temperature (RT) when the concentration of acidic sites was high $(0.158 \mathrm{mmol} / \mathrm{g})$. The reaction was negligible when the concentration of the acidic sites was low $(0.1 \mathrm{mmol} / \mathrm{g})$ at RT. However, the propene showed no reactivity with the highly acidic SAPO-34 at low temperatures, i.e., $-56^{\circ} \mathrm{C}$ (using octane + dry ice), -20 ${ }^{\circ} \mathrm{C}$ (using $\mathrm{NaCl}+$ ice), and $0{ }^{\circ} \mathrm{C}$ (using ice + water). In general, low-temperature conditions were found to be helpful in inhibiting the chemisorption of propene on the highly acidic H-SAPO-34 catalysts, which can facilitate propene separation and allow for reliable monitoring of kinetic parameters.
\end{abstract}

Keywords: zeolites; SAPO-34; catalytic mechanism; adsorption; separation; propene; catalysts regeneration

\section{Introduction}

SAPO-34 zeolite plays a pivotal role in the chemical industry [1]. One of its important applications is in a methanol-to-olefins (MTO) process [2-5]. Recently, the Chinese government has passed an agreement to scale up MTO processes in tons per year and many operational units are expected in the coming years [6]. The most desirable product generated in this process is propene. There are certain 
issues related to this product, including separation of propene from its mixture [7-9] and design of new catalytic materials to increase its production yield, stability, and recyclability [9-16]. To understand and cope with these issues, researchers are exploring different strategies. One of the approaches is to study the diffusion behavior of propene on SAPO-34. Such studies require experimental data free of any coupling or oligomerization reactions. Some literature have shown that propene reacts with zeolites [13,17-21]. However, exact conditions of propene-zeolite reaction remain unclear, that is, whether propene reacts with every zeolite or whether there are exceptional circumstances is unknown. Recently, Wang et al. [22] showed that an experimental curve of propene uptake on SAPO-34 zeolite did not reach equilibrium but continued to decline with time, which was attributed to the slow chemical reaction (i.e., slow chemisorption), whereas a simulation uptake curve showed fitted linear equilibrium (i.e., physisorption), which is different from the experimental uptake curve after $20 \mathrm{~s}$ (see Figure S1; Supplementary Materials). In order to further explore this behavior, we have designed and examined a new experimental approach, that is, using various types of acidic SAPO-34 zeolites at different temperatures, to understand the reactivity and reproducibility of propene in a vacuum adsorption system. The schematic of the vacuum adsorption system is shown in Figure 1.

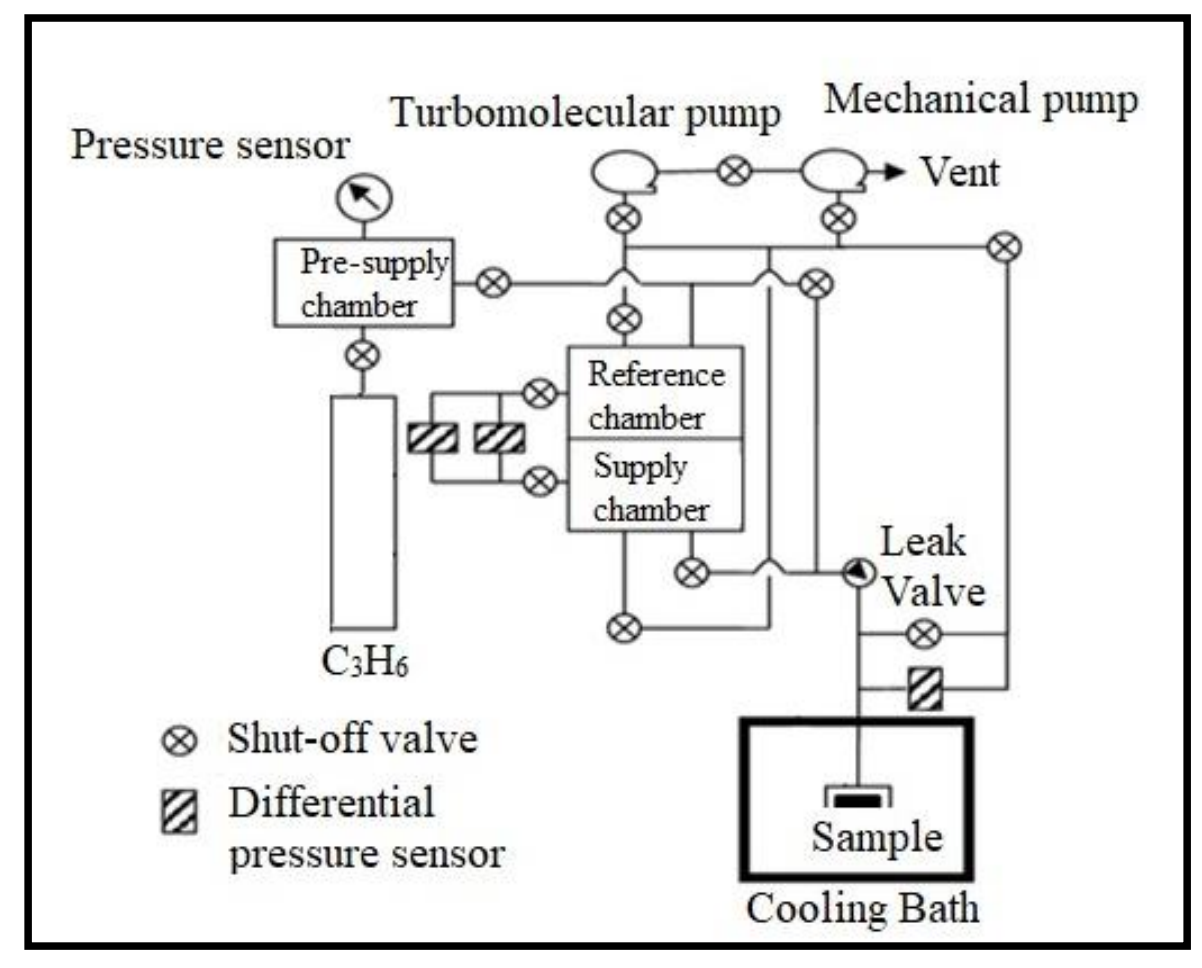

Figure 1. Schematic of a vacuum adsorption apparatus.

\section{Results and Discussions}

In order to examine the propene-SAPO-34 interaction, different batches of SAPO-34 zeolites were prepared with different strengths of acidity by controlling zeolite alumina and silica components. A higher ratio of silica to alumina was used to produce the SAPO-34 with higher acidity, and SAPO-34 patterns were characterized by X-ray powder diffraction (XRD) (as shown in Figure 2A), which are comparable to the reported SAPO-34 XRD patterns [2,23]. The XRD patterns of moderately acidic zeolite show relatively sharp peaks, reflecting the highest crystallinity of the materials similar to the results in the reported literature [2]. The morphology and size of three types of zeolites were observed by scanning electron microscopy (SEM). The SEM images in Figure 3 are similar in morphology for high-, moderate-, and low-silica SAPO-34. 


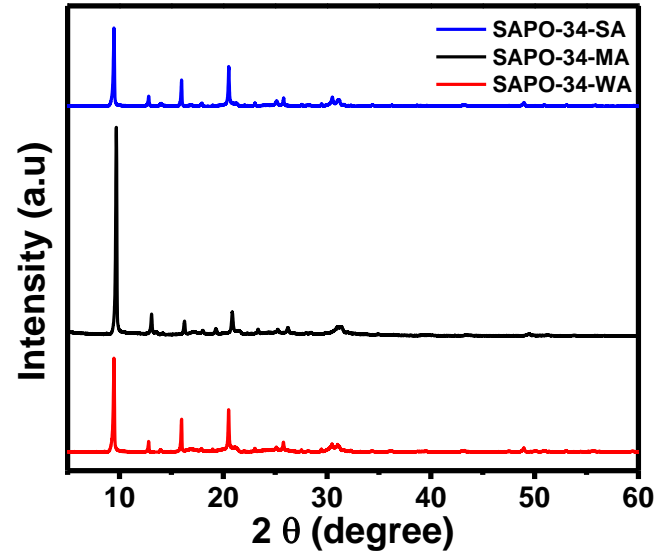

(A)

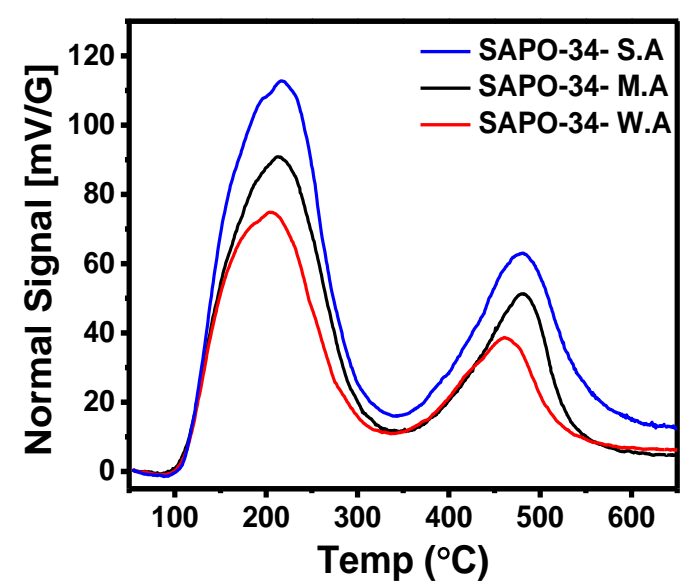

(B)

Figure 2. (A) XRD patterns of SAPO-34 zeolite samples. (B) Acidic strengths of SAPO-34 zeolites by temperature-programmed desorption of ammonia ( $\left.\mathrm{NH}_{3}-\mathrm{TPD}\right)$. SA, MA, and WA represent strongly, moderately, and weakly acidic H-SAPO-34 zeolites, respectively.

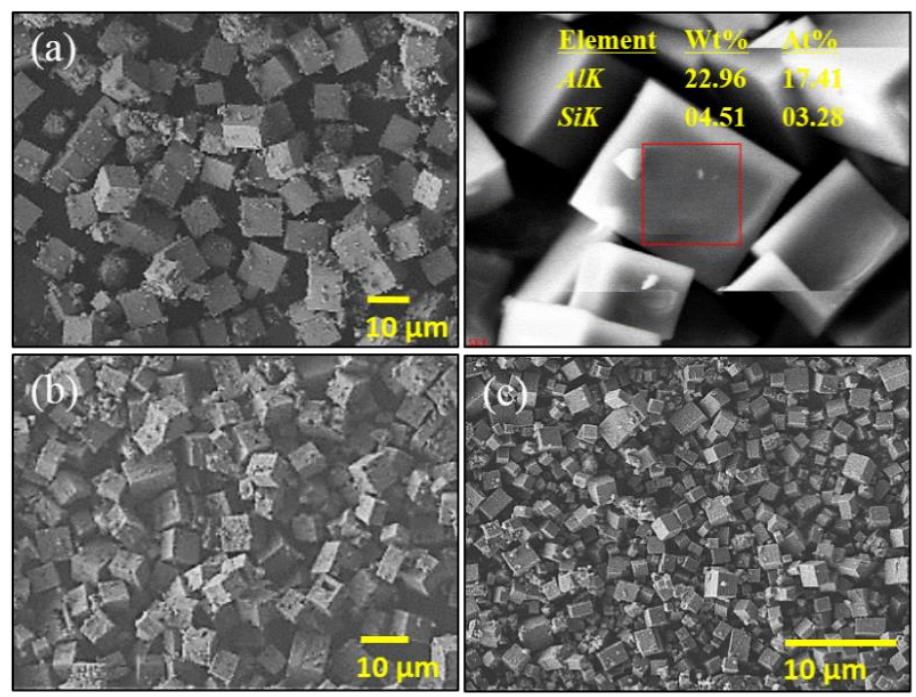

Figure 3. FESEM images of strongly acidic (a), moderately acidic (b), and weakly acidic (c) H-SAPO-34 zeolites. Top right shows the EDX results for strongly acidic H-SAPO-34.

In moderately acidic SAPO-34 zeolites, large surface holes distributions were observed as mentioned in an earlier study by Li et al. [2]. Similarly, low-silicon SAPO-34 has a small cubic structure different from results in the literature [24] and layered SAPO-34 [25]. Even though there is a slight variation in particle size, the chemical nature and crystal structure of prepared zeolites are the same. The high-silica zeolite results in bigger particles compared to the low-silica zeolite having small particle sizes. Different particle sizes do not affect the chemisorption as the chemisorption depends only on the strength of acidic sites.

The density of acid sites was measured by temperature-programmed desorption of ammonia ( $\mathrm{NH}_{3}$-TPD). The desorption peaks below 200, 200-400, and 400-600 ${ }^{\circ} \mathrm{C}$ were considered as weakly, moderately, and strongly acidic, respectively [26-29]. As shown in Figure 2B, the ammonia desorption peaks of all three SAPO-34 zeolites confirmed the presence of both weakly and strongly acidic sites but the relative ratio of total acidic sites varies the increases in direct correlation according to the $\mathrm{Si} / \mathrm{Al}$ ratio. The quantitative analysis was also done by measuring the area under the curve of ammonia desorption peak and the results were presented in Table 1. The strongly acidic zeolite has a total concentration of $1.58 \mathrm{mmol} / \mathrm{g}$, which is consistent with that for a Si/Al ratio of 0.19 calculated by 
the SEM-EDX technique. Figure $3 b$ shows the SEM-EDX results for the strongly acidic SAPO-34. An elemental weight ratio and an atomic weight ratio give values of 0.196 and 0.188 , respectively. Similarly, the Si/Al ratios of moderately and weakly acidic zeolite were calculated as 0.15 and 0.097 , respectively. The results of $\mathrm{NH}_{3}$-TPD and SEM-EDX values reflect the successful synthesis of three different acidic SAPO-34 zeolites.

Table 1. Quantitative acidic properties.

\begin{tabular}{ccc}
\hline SAPO-34 & Si/Al Ratio & Total Acid Density $(\mu \mathrm{mol} / \mathrm{g})$ \\
\hline Strongly acidic & 0.191 & 158 \\
Moderately acidic & 0.155 & 125 \\
Weakly acidic & 0.097 & 82 \\
\hline
\end{tabular}

The measurements of propene sorption isotherm on the three H-SAPO-34 zeolites were performed using a volumetric vacuum adsorption apparatus (manometry). The setup and procedure were described by Kobayashi et al. [30]. Propene uptake was performed on an activated zeolite, at $400{ }^{\circ} \mathrm{C}$ for $6 \mathrm{~h}$ under an ultra-high vacuum pressure $\left(3.0 \times 10^{-4} \mathrm{~Pa}\right)$ in successive doses. At first, the zeolite surfaces were saturated by propene gas at room temperature (RT) to cover the sites of irreversible adsorption (chemisorption) and the cell was evacuated at RT under a high vacuum pressure $\left(3.0 \times 10^{-4} \mathrm{~Pa}\right)$, so that the subsequent measurement was performed only on a reversibly adsorbed (physisorbed) propene at RT, which was called cycle-1. After cycle-1, the sample at the same temperature was degassed for $2 \mathrm{~h}$ under a vacuum pressure $\left(3.0 \times 10^{-4} \mathrm{~Pa}\right)$ and tested for the second run of adsorption at RT, in order to measure the re-adsorbed amount, which was defined as cycle-2. The difference of propene adsorption on the highly acidic SAPO- 34 between cycle- 1 and cycle- 2 showed the occurrence of oligomerization of propene on the zeolite surface, while in case of physisorption, identical adsorption occurs in both cycle- 1 and cycle-2. In order to obtain accurate data for each dose, we recorded the adsorption equilibrium at a fixed point, because equilibrium never occurs in highly acidic zeolite due to the very slow reaction of propene with strongly acidic cages of zeolites [22]. As shown in Figure 4A, the zeolite with strong acidity shows that cycle- 1 and cycle- 2 are not the same and illustrates no reproducibility. The moderately acidic SAPO-34 also shows no reproducibility (Figure 4B), but it is seen that the difference of propene adsorption on The moderately acidic SAPO- 34 between cycle- 1 and cycle- 2 is smaller, reflecting the less chemisorption compare to that in the highly acidic zeolite. Figure $4 \mathrm{C}$ shows the adsorption of propene on the weakly acidic SAPO-34 in cycle- 1 and cycle- 2 . It can be seen that the adsorbed amounts in cycle- 1 and cycle- 2 are the same. Thus, the physisorption or chemisorption depends on the acidity of SAPO-34 zeolite.

In order to further study the temperature effect on the reactivity of propene in highly and moderately acidic zeolites, we performed propene adsorption isotherm at low temperatures in various cooling baths. These cooling baths were mixtures of octane + dry ice $\left(-56^{\circ} \mathrm{C}\right), \mathrm{NaCl}+$ ice $\left(-20^{\circ} \mathrm{C}\right)$, and ice + water $\left(0^{\circ} \mathrm{C}\right)$. The propene adsorption experiments were carried out at different temperatures and revealed that the highly acidic zeolite shows completely reproducible results at temperatures of $-56,-20$, and $0{ }^{\circ} \mathrm{C}$. Figure $4 \mathrm{D}$ shows the propene adsorption in cycle- 1 and cycle- 2 at $0{ }^{\circ} \mathrm{C}$. It is noted that the weakly acidic SAPO-34 adsorptions in cycle- 1 and cycle- 2 are identical at RT, reflecting the physisorption behavior; however, the absorbed amounts of propene in cycle- 1 and cycle- 2 are not the same for the moderately and highly acidic SAPO-34, reflecting the chemisorption of propene on high-acid-density SAPO- 34 at $25^{\circ} \mathrm{C}$. The degree of chemisorption for the moderately acidic SAPO- 34 is lower than that for the strongly acidic one, reflecting the direct influence of the acid density on chemisorption. When the temperature was kept at zero and below zero, identical adsorption in cycle-1 and cycle- 2 are shown for the strongly acidic zeolite, reflecting that there is no chemical reaction or the chemisorption is slow enough so it could be ignored (see also Figure 5). These results of propene adsorption on the three different acidic zeolites and their adsorption analyses at different temperatures provide useful information for computational researchers to choose the correct acidity and adsorption 
temperature while using propene as the adsorbate. It is also beneficial to use the cooling bath for separation of propene from propane or its mixture when there is a chance of a chemical reaction. These results are also helpful in preparing zeolites with specific acidity to avoid chemisorption of products and hence increase the overall lifetime of the catalyst.
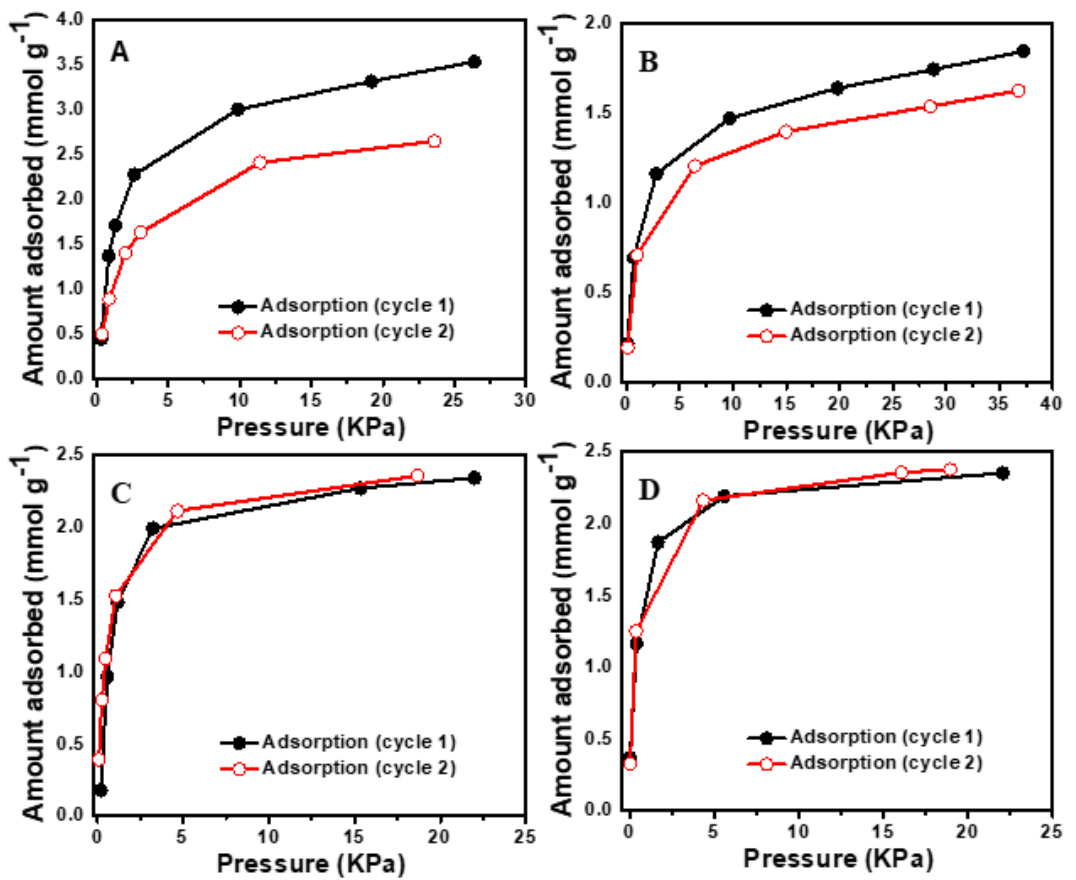

Figure 4. Adsorption (cycle-1) and re-adsorption (cycle-2) of propene on SAPO-34 zeolites with different acidic strengths: (A) strong acidity at room temperature (RT), (B) moderate acidity at RT, (C) weak acidity at RT, and (D) strong acidity at $0{ }^{\circ} \mathrm{C}$.

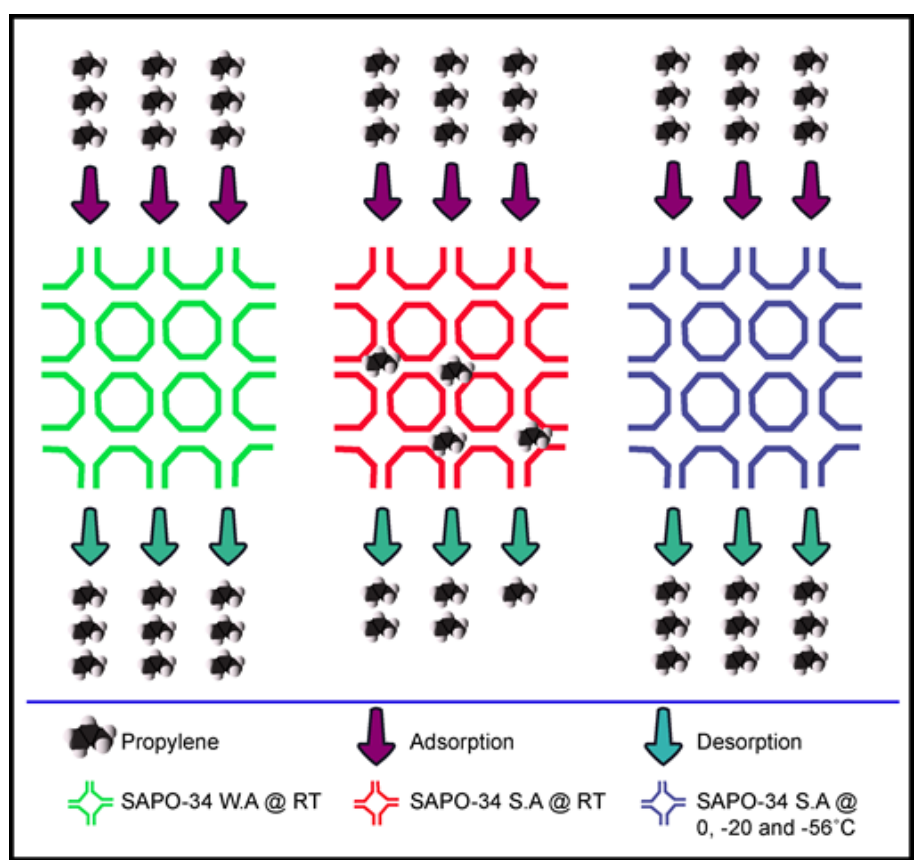

Figure 5. Schematic presentation of propene adsorption and chemisorption on SAPO-34 zeolites with various acidic strengths at different temperatures. 


\section{Materials and Methods}

Three different acidic SAPO-34 zeolites were synthesized by a hydrothermal method with some modification in initial stoichiometric ratios of silica to alumina. The silicon source was silica gel (40 $\mathrm{wt} \%$ $\mathrm{SiO}_{2}$ ) (Silica sol Qingdao Co, Ltd., Qingdao, China), and the aluminum source was $73 \mathrm{wt} \% \mathrm{Al}_{2} \mathrm{O}_{3}$ (Chalco Shandong co. Ltd., Shandong, China), the phosphorus source was phosphoric acid ( $\left.85 \mathrm{wt} \% \mathrm{H}_{3} \mathrm{PO}_{4}\right)$ (Tianjin Ronghong chemical co. Ltd., Tianjin, China), and the template was tetraethylammonium (TEA) (Tianjin Yongda Chemical Reagent Co., Ltd., Tianjin, China). Liquid compositions were used in ratios of $\mathrm{Al}_{2} \mathrm{O}_{3}: \mathrm{xSiO}_{2}: 1.15 \mathrm{P}_{2} \mathrm{O}_{5}: 2.7 \mathrm{TEA}: 114 \mathrm{H}_{2} \mathrm{O}(\mathrm{x}=0.05-0.5)$. By changing the content of $\mathrm{Si}$ in the catalyst solution, three kinds of the skeleton of silicon content were obtained. For $x=0.5$ was synthesized, a catalyst with a high $\mathrm{Si} / \mathrm{Al}$ ratio was obtained. For $\mathrm{x}=0.25$, a catalyst with moderate acidity was obtained. For $\mathrm{x}=0.05$, a catalyst with a low Si/Al ratio was obtained called as the weakly acidic SAPO-34 zeolite. The crystal structure of the sample was characterized by XRD (Bruker D8/Advance, CO, USA). Cu K $\alpha$ X-ray was used as the X-ray source. Diffraction intensities were recorded from $5^{\circ}$ to $80^{\circ}$ at a rate of $5^{\circ} / \mathrm{min}$. The observed diffraction patterns were assigned by referring to the Joint Committee on the Powder Diffraction Standards (JCPDS) card. The morphology of the zeolite was characterized by SEM (JSE-6700F, JEOL, CA, USA). Acid site density was calculated from $\mathrm{NH}_{3}$-TPD measurement. The sample was first heated up to $400{ }^{\circ} \mathrm{C}$ under the He flow and kept for $2 \mathrm{~h}$. After cooling down to $100^{\circ} \mathrm{C}$, it was exposed to the $\mathrm{NH}_{3}$ flow for $1 \mathrm{~h}$ and then to the He flow for $1 \mathrm{~h}$ to remove excessive $\mathrm{NH}_{3}$. Then, the temperature was increased up to $650{ }^{\circ} \mathrm{C}$ at a rate of 10 ${ }^{\circ} \mathrm{C} / \mathrm{min}$. The desorption signal of $\mathrm{NH}_{3}$ from the sample was detected by a thermal conductivity detector. The acid site density was also calculated from the EDS analysis of the Si/Al ratio.

\section{Conclusions}

We have successfully developed three H-SAPO-34 zeolites with a similar morphology but different acid properties as evidenced by the XRD, FESEM, EDX, and $\mathrm{NH}_{3}$-TPD measurements. It was obvious that the extent of zeolite-propene interaction, diffusional properties, and adsorptive properties were all dependent on the zeolite acidities and adsorption conditions. At RT, propene separation and diffusion characteristics could be observed on the weakly acidic H-SAPO-34 zeolite. On the other hand, low-temperature conditions are necessary to avoid chemisorption and to establish similar features with the highly acidic H-SAPO-34 zeolite. The results have, therefore, shed useful information on the behavior of propene in H-SAPO-34, separation of propene from other gases, and would be beneficial in further elucidating the mechanism and stability of catalysts in MTO reaction.

Supplementary Materials: The following are available online at http://www.mdpi.com/2073-4344/9/11/919/s1, Figure S1: Experimental and simulated uptake curves for propane and propene in SAPO-34. (Source, F. Wang, Y. Kobayashi, U. Muhammad, D. Wang, Y. Wang, Review of Scientific Instruments 2016, 87, 036101), including experimental and simulated uptake curves for propane and propene in SAPO-34, and the calculation method of the adsorb gases.

Author Contributions: Conceptualization, M.U. and J.Z.; methodology, K.C. and M.T.A.; software, I.K. and A.K.; validation, M.U., A.G. and Z.H.Y.; formal analysis, A.H. and O.M.; investigation, M.U., B.A.A.-M., J.Z. and K.C.; writing—original draft preparation, M.U., J.Z., A.G. and A.K.; writing—review and editing, M.U., O.M. and Z.H.Y.

Funding: This research received no external funding.

Acknowledgments: First and foremost, we are grateful to Wang Dezheng, Wang Yao, and Wei Fei (Department of Chemical Engineering, Tsinghua University, Beijing, P. R. China) for their useful advice and their experimental support. We are also thankful to Tsinghua University and Center of Excellence in Nanotechnology, King Fahd University of Petroleum \& Minerals for the research facilities, and Saudi Aramco Chair Programme (ORCP2390).

Conflicts of Interest: The authors declare no conflicts of interest.

\section{References}

1. Ashtekar, S.; Satyanarayana, C.V.V.; Chakrabarty, D.K. Silicon-substituted aluminophosphate molecular sieves: Studies on SAPO-5, -11, -34 and -44. J. Chem. Sci. 1994, 106, 621-628. 
2. Li, Y.; Zhang, M.; Wang, D.; Wei, F.; Wang, Y. Differences in the methanol-to-olefins reaction catalyzed by SAPO-34 with dimethyl ether as reactant. J. Catal. 2014, 311, 281-287. [CrossRef]

3. Yu, Y.; Qin, J.; Xiao, M.; Wang, S.; Han, D.; Meng, Y. Performance Enhanced SAPO-34 Catalyst for Methanol to Olefins: Template Synthesis Using a CO2-Based Polyurea. Catalysts 2018, 9, 16. [CrossRef]

4. Zhang, Y.; Ren, Z.; Wang, Y.; Deng, Y.; Li, J. Synthesis of Small-Sized SAPO-34 Crystals with Varying Template Combinations for the Conversion of Methanol to Olefins. Catalysts 2018, 8, 570. [CrossRef]

5. Jarvelin, H.; James, R.F. Adsorptive separation of propylene-propane mixtures. Ind. Eng. Chem. Res. 1993, 32, 2201-2207. [CrossRef]

6. Tian, P.; Wei, Y.; Ye, M.; Liu, Z. Methanol to Olefins (MTO): From Fundamentals to Commercialization. ACS Catal. 2015, 5, 1922-1938. [CrossRef]

7. Pan, Y.; Li, T.; Lestari, G.; Lai, Z. Effective separation of propylene/propane binary mixtures by ZIF-8 membranes. J. Membr. Sci. 2012, 390, 93-98. [CrossRef]

8. Luo, M.; Wang, D.; Hu, B.; Fu, Y.; Mao, G.; Wang, B. The Molecular Structure and Morphology of Insoluble Coke in SAPO-34 Catalyst. Chem. Sel. 2017, 2, 5458-5462. [CrossRef]

9. Sivaram, S. Recent advances in the polymerisation of propylene. J. Chem. Sci. 1983, 92, 613-621.

10. Chen, D.; Moljord, K.; Holmen, A. A methanol to olefins review: Diffusion, coke formation and deactivation on SAPO type catalysts. Microporous Mesoporous Mater. 2012, 164, 239-250. [CrossRef]

11. Zhu, J.; Li, Y.; Muhammad, U.; Wang, D.; Wang, Y. Effect of alkene co-feed on the MTO reactions over SAPO-34. J. Chem. Sci. 2017, 316, 187-195. [CrossRef]

12. Hu, B.; Wang, D.; Gao, S.; Zhang, X.; Mao, G.; Wang, B.; Luo, M. NH3 Competitive Adsorbed FTIR: A Potential Method to Investigate the Confined Species-Acidic Sites Interaction in SAPO-34 Catalyst. Chem. Sel. 2016, 1, 5493-5496.

13. Kumar, A.V.A.; Yashonath, S.; Ananthakrishna, G. Influence of temperature inhomogeneity on product profile of reactions occurring within zeolites. J. Chem. Sci. 2003, 115, 543-552. [CrossRef]

14. Li, D.; Zhang, H.; Usman, M.; Li, Z.; Han, L.; Li, C.; Zhang, S. Study on the hydrotreatment of C9 aromatics over supported multi-metal catalysts on $\gamma$-Al2O3. J. Renew. Sustain. Energy 2014, 6, 033132. [CrossRef]

15. Standl, S.; Hinrichsen, O. Kinetic Modeling of Catalytic Olefin Cracking and Methanol-to-Olefins (MTO) over Zeolites: A Review. Catalysts 2018, 8, 626. [CrossRef]

16. Guo, Z.; Miao, P.; Zhu, W.; Guo, L.; Li, F.; Xue, Y.; Yin, Q.; Yuan, R.; Xu, L. Synthesis of SAPO-34 Molecular Sieves via Novel Intermittent Hydrothermal Treatment and Its Effect on the Crystallization and Product Properties. Catalysts 2017, 7, 150. [CrossRef]

17. Hu, B.; Mao, G.; Wang, D.; Fu, Y.; Wang, B.; Luo, M. Conversion and coking of olefins on SAPO-34. Catal. Sci.Tech. 2017, 7, 5785-5794. [CrossRef]

18. Wilshier, K.G.; Smart, P.; Western, R.; Mole, T.; Behrsing, T. Oligomerization of propene over H-ZSM-5 zeolite. Appl. Catal. 1987, 31, 339-359. [CrossRef]

19. Yarlagadda, P.; Lund, C.R.F.; Ruckenstein, E. Oligomerization of ethene and propene over composite zeolite catalysts. Appl. Catal. 1990, 62, 125-139. [CrossRef]

20. Mlinar, A.N.; Baur, G.B.; Bong, G.G.; Getsoian, A.B.; Bell, A.T. Propene oligomerization over Ni-exchanged Na-X zeolites. J. Catal. 2012, 296, 156-164. [CrossRef]

21. Deimund, M.A.; Labinger, J.; Davis, M.E. Nickel-Exchanged Zincosilicate Catalysts for the Oligomerization of Propylene. ACS Catal. 2014, 4, 4189-4195. [CrossRef]

22. Wang, F.; Kobayashi, Y.; Muhammad, U.; Wang, D.; Wang, Y. Note: Molecular diffusivity in a small pore zeolite measured by a variable pressure (piezometric) uptake method. Rev. Sci. Instrum. 2016, 87, 036101. [CrossRef] [PubMed]

23. Wei, Y.; Zhang, D.; Liu, Z.; Su, B.-L. Highly efficient catalytic conversion of chloromethane to light olefins over HSAPO-34 as studied by catalytic testing and in situ FTIR. J. Catal. 2006, 238, 46-57. [CrossRef]

24. Yang, S.-T.; Kim, J.-Y.; Chae, H.-J.; Kim, M.; Jeong, S.-Y.; Ahn, W.-S. Microwave synthesis of mesoporous SAPO-34 with a hierarchical pore structure. Mater. Res. Bull. 2012, 47, 3888-3892. [CrossRef]

25. Sommer, L.; Mores, D.; Svelle, S.; Stöcker, M.; Weckhuysen, B.M.; Olsbye, U. Mesopore formation in zeolite H-SSZ-13 by desilication with NaOH. Microporous Mesoporous Mater. 2010, 132, 384-394. [CrossRef]

26. Usman, M.; Li, D.; Razzaq, R.; Yaseen, M.; Li, C.; Zhang, S. Novel MoP/HY catalyst for the selective conversion of naphthalene to tetralin. J. Environ. Chem. Eng. 2015, 23, 21-26. [CrossRef] 
27. Zhang, H.H.; Cao, Y.M.; Usman, M.; Li, L.J.; Li, C.S. Study on the Hydrotreating Catalysts Containing Phosphorus of Coal Tar to Clean Fuels. Adv. Mater. Res. 2012, 531, 263-267. [CrossRef]

28. Usman, M.; Li, D.; Razzaq, R.; Latif, U.; Muraza, O.; Yamani, Z.H.; Al-Maythalony, B.A.; Li, C.; Zhang, S. Poly aromatic hydrocarbon (naphthalene) conversion into value added chemical (tetralin): Activity and stability of MoP/AC catalyst. J. Environ. Chem. Eng. 2018, 6, 4525-4530. [CrossRef]

29. Ullah, L.; Zhao, G.; Xu, Z.; He, H.; Usman, M.; Zhang, S. 12-Tungstophosphoric acid niched in Zr-based metal-organic framework: A stable and efficient catalyst for Friedel-Crafts acylation. Sci. China Chem. 2018, 61, 402-411. [CrossRef]

30. Kobayashi, Y.; Wang, F.; Li, Q.X.; Wang, D.Z. A microscopic model of the Tian-Calvet microcalorimeter, cell design for a faster response, and measurement by a continuous procedure. Rev. Sci. Instrum. 2014, 85, 034101. [CrossRef]

(C) 2019 by the authors. Licensee MDPI, Basel, Switzerland. This article is an open access article distributed under the terms and conditions of the Creative Commons Attribution (CC BY) license (http://creativecommons.org/licenses/by/4.0/). 